\title{
A novel atrial volume reduction technique to enhance the Cox maze procedure: Initial results
}

Akira Marui, MD, PhD, Takeshi Nishina, MD, PhD, Keiichi Tambara, MD, PhD, Yoshiaki Saji, MD, Takeshi Shimamoto, MD, Masahiko Nishioka, MD, Tadashi Ikeda, MD, PhD, and Masashi Komeda, MD, PhD

From the Department of Cardiovascular Surgery, Kyoto University Graduate School of Medicine, Kyoto, Japan.

Received for publication March 6, 2006; revisions received July 3, 2006; accepted for publication July 7, 2006.

Address for reprints: Masashi Komeda, $\mathrm{MD}, \mathrm{PhD}$, Department of Cardiovascular Surgery, Kyoto University Graduate School of Medicine, 54 Shogoin-Kawara, Sakyo, Kyoto 606-8507, Japan (E-mail: komelab@ kuhp.kyoto-u.ac.jp).

J Thorac Cardiovasc Surg 2006;132:1047-53 $0022-5223 / \$ 32.00$

Copyright $\odot 2006$ by The American Association for Thoracic Surgery

doi:10.1016/j.jtcvs.2006.07.020
Objective: Large left atrial diameter is reported to be a predictor for recurrent atrial fibrillation after the Cox maze procedure, and left atrial diameter by itself influences the chance of sinus rhythm recovery, as well as maintenance of sinus rhythm. However, additional cut-and-sew procedures to decrease left atrial diameter extend operative time and can cause bleeding. Thus we developed a no-bleeding, faster, and therefore less invasive left atrial volume reduction technique to enhance the Cox maze procedure.

Methods: The modified Cox maze III procedure with cryoablation or the left atrial maze procedure in association with mitral valve surgery was performed in 80 patients with atrial fibrillation and enlarged left atria $(\geq 60 \mathrm{~mm})$. Among them, 44 patients had the concomitant volume reduction technique (VR group); continuous horizontal mattress sutures for left atrial plication were placed on the left atrial wall along the pulmonary vein isolation line. Cryoablation was applied to the suture line so that the plicated left atrium is anatomically and electrically isolated. Another 36 patients did not have the volume reduction technique (control group).

Results: The VR group had preoperative left atrial diameters similar to those of the control group ( $67.1 \pm 7.8$ vs $64.5 \pm 6.7 \mathrm{~mm})$ and a longer preoperative duration of atrial fibrillation (14.1 \pm 5.4 vs $9.5 \pm 5.1$ years, $P<.05)$ but had smaller postoperative left atrial diameters ( $47.6 \pm 6.3$ vs $62.1 \pm 7.9 \mathrm{~mm}, P<.01)$. There were no differences in mean crossclamp/bypass time and chest tube drainage for 12 hours between the groups. Twelve months after surgical intervention, the sinus rhythm recovery rate of the VR group was better than that of the control group $(90 \%$ vs $69 \%, P<.05)$.

Conclusions: Even in patients with long-standing atrial fibrillation and an enlarged left atrium, maze procedures concomitant with the novel left atrial volume reduction technique improved the sinus rhythm recovery rate without increasing complications. Although further study with a larger number of patients and a longer follow-up period is needed, this safe and thus far potent technique that catheter-based ablation cannot copy might extend indication of the Cox maze procedure for patients with tough atrial fibrillation.

$\mathrm{T}$ he Cox maze procedure has been a gold standard in the surgical treatment of atrial fibrillation (AF). ${ }^{1-4}$ Recently, however, this complex technique has shifted to simple procedures, such as pulmonary vein (PV) isolation with radiofrequency ablation devices, ${ }^{5-8}$ because the conventional full maze procedure is time consuming, prone to bleeding, and technically demanding. However, sinus rhythm (SR) recovery rates with the new devices are insufficient, particularly in patients with long-standing AF and a large left atrium (LA). These factors are reported to cause recurrent $\mathrm{AF}$ after the Cox maze procedure. ${ }^{9,10}$ Therefore a more effective but less invasive technique is desirable for the treatment of these patients.

The enlarged LA is a major factor in the initiation and maintenance of AF. ${ }^{11,12}$ Farnsworth and associates ${ }^{13,14}$ reported that LA volume reduction (VR) by itself is 


\author{
Abbreviations and Acronyms \\ $\mathrm{A} / \mathrm{E}=$ ratio of peak $\mathrm{A}$ to peak $\mathrm{E}$ wave \\ $\mathrm{AF}=$ atrial fibrillation \\ $\mathrm{ECG}=$ electrocardiography \\ LA $=$ left atrium \\ $\mathrm{LAD}=$ left atrial diameter \\ PV = pulmonary vein \\ $\mathrm{RA}=$ right atrium \\ $\mathrm{SR}=$ sinus rhythm \\ $\mathrm{VR}=$ volume reduction
}

helpful in the elimination of AF with mitral valve disease. Therefore combination of the Cox maze procedure with LA VR might facilitate SR recovery, as well as SR maintenance. However, additional cut-and-sew procedures to decrease LA size further extend operative time and might cause bleeding.

Therefore in the present study we developed a lessinvasive, no-bleeding LA VR technique that might enhance the Cox maze procedure. This novel technique does not require additional cut-and-sew procedures by using LA plication and confinement cryoablation that enables anatomic and electrical isolation of PVs and plicated LA area.

\section{Patients and Methods \\ Patients}

Between June 1999 and December 2005, 123 patients with chronic $\mathrm{AF}$ underwent maze procedures associated with mitral valve surgery in our institute. Among them, 80 patients with enlarged LAs (diameter $\geq 60 \mathrm{~mm}$ ) with or without long-standing AF (preoperative duration of $\mathrm{AF} \geq 5$ years) were included in the present study. Left atrial diameter (LAD) was measured by means of M-mode transthoracic echocardiography. Among the 80 patients, 36 underwent the maze procedure alone before June 2002 (control group). After June 2002, 44 patients underwent the maze procedure concomitantly with the novel VR technique (VR group, Table 1). The VR group had a longer duration of AF than the control group (14.1 \pm 5.4 vs $9.5 \pm 5.1$ years, respectively; $P<.05$ ). Preoperative LAD was not different between the groups $(67.1 \pm 7.8$ vs $64.5 \pm 6.7 \mathrm{~mm})$.

\section{Operative Procedure}

The maze procedures were primarily based on the modified Cox maze III procedure with cryoablation or the LA maze procedure..$^{2-4,15-17}$ After median sternotomy, standard cardiopulmonary bypass with mild hypothermia and cold blood cardioplegia was established. Mitral valve repair or prosthetic valve replacement was performed immediately before or after the VR technique. The same surgeon (M.K.) operated on all patients in a homogenous fashion during the whole study period.

\section{Less-invasive VR Technique by Means of LA Plication and Confinement Cryoablation}

LA plication with continuous horizontal mattress sutures. A standard right-sided left atriotomy was performed parallel to the interatrial groove and extended toward the upper and inferior margin
TABLE 1. Patient characteristics

\begin{tabular}{|c|c|c|c|}
\hline Characteristic & VR group & Control group & $P$ value \\
\hline Patients (n) & 44 & 36 & - \\
\hline Male sex $(\%)$ & $17(39)$ & $14(39)$ & NS \\
\hline Age (y) & $61.4 \pm 13.7$ & $64.8 \pm 10.3$ & NS \\
\hline NYHA class & $2.6 \pm 0.8$ & $2.5 \pm 0.8$ & NS \\
\hline $\begin{array}{l}\text { Previous cardiac } \\
\text { surgery, n (\%) }\end{array}$ & $4(9)$ & $2(6)$ & NS \\
\hline History of stroke, $\mathrm{n}(\%)$ & $3(7)$ & $1(3)$ & NS \\
\hline $\begin{array}{l}\text { Coronary artery } \\
\text { disease, } \mathrm{n}(\%)\end{array}$ & $4(9)$ & $4(11)$ & NS \\
\hline \multicolumn{4}{|l|}{ Mitral valve disease } \\
\hline Rheumatic, n (\%) & $24(55)$ & $18(50)$ & NS \\
\hline Myxomatous, n (\%) & $16(36)$ & $16(44)$ & NS \\
\hline Ischemic, n (\%) & $4(9)$ & $2(6)$ & NS \\
\hline \multicolumn{4}{|l|}{ Aortic valve disease } \\
\hline AS & $2(5 \%)$ & $2(6 \%)$ & NS \\
\hline $\mathrm{AR}$ & $2(5 \%)$ & $3(8 \%)$ & NS \\
\hline ASR/ARS & $5(11 \%)$ & $5(14 \%)$ & NS \\
\hline Duration of $A F(y)$ & $14.1 \pm 5.4$ & $9.5 \pm 5.1$ & $<.05$ \\
\hline \multicolumn{4}{|l|}{ Type of AF } \\
\hline Permanent & $34(78 \%)$ & $26(72 \%)$ & NS \\
\hline Persistent & $7(22 \%)$ & $10(28 \%)$ & NS \\
\hline F-wave in V1 (mV) & $0.18 \pm 0.12$ & $0.16 \pm 0.09$ & NS \\
\hline \multicolumn{4}{|l|}{ Echocardiography } \\
\hline LA diameter $(\mathrm{mm})$ & $67.1 \pm 7.8$ & $64.5 \pm 6.7$ & NS \\
\hline LVDd (mm) & $56.4 \pm 8.3$ & $55.2 \pm 12.3$ & NS \\
\hline LVDs (mm) & $36.8 \pm 8.4$ & $35.9 \pm 8.8$ & NS \\
\hline LVEF (\%) & $50.1 \pm 13.4$ & $54.3 \pm 14.7$ & NS \\
\hline FS $(\%)$ & $29.2 \pm 6.8$ & $32.3 \pm 7.5$ & NS \\
\hline
\end{tabular}

$V R$, Volume reduction; NS, not significant; NYHA, New York Heart Association; $A S$, aortic stenosis; $A R$, aortic regurgitation; $A S R$, aortic stenosis and regurgitation (stenosis $>$ regurgitation); $A R S$, aortic regurgitation and stenosis (regurgitation $>$ stenosis); $A F$, atrial fibrillation; $L A$, left atrium; $L V D$ d, left ventricular diastolic dimension; $L V D s$, left ventricular systolic dimension; $L V E F$, left ventricular ejection fraction; $F S$, fractional shortening.

of the left PVs. The enlarged LA is plicated mainly between the mitral annulus and the left PVs and additionally plicated with sutures along the right-sided left atriotomy (Figure 1, A). Although continuous horizontal mattress sutures were placed on the redundant LA wall between the mitral annulus and the left PVs (Figures 1, B, and 2, $A$ and $B$ ), the suture was placed at least $2 \mathrm{~cm}$ away from the mitral annulus to maintain postoperative LA function. The suture was tightened so that the redundant LA was excluded toward the outside of the LA cavity (Figure 1, B).

Confinement cryoablation. Subsequently, to establish isolation of PVs, as well as isolation of the LA plicated area, confinement cryoablation $\left(-80^{\circ} \mathrm{C}\right.$ for 2 minutes with a $20^{\circ}$, angled, $3-\mathrm{cm}$ linear probe that was specially designed) was applied onto the horizontal mattress suture line, and then the plicated LA area was anatomically and electrically isolated (Figures 1, $C$, and 2, $A$ and $B$ ). The LA appendage was plicated from inside, and the suture line was cryoablated. Other cryoablations were applied to the LA, as shown in Figure 2. The right-sided left atriotomy was closed with a continuous suture so that the right side of the LA was further plicated (Figures 1, C, and 2,B). 

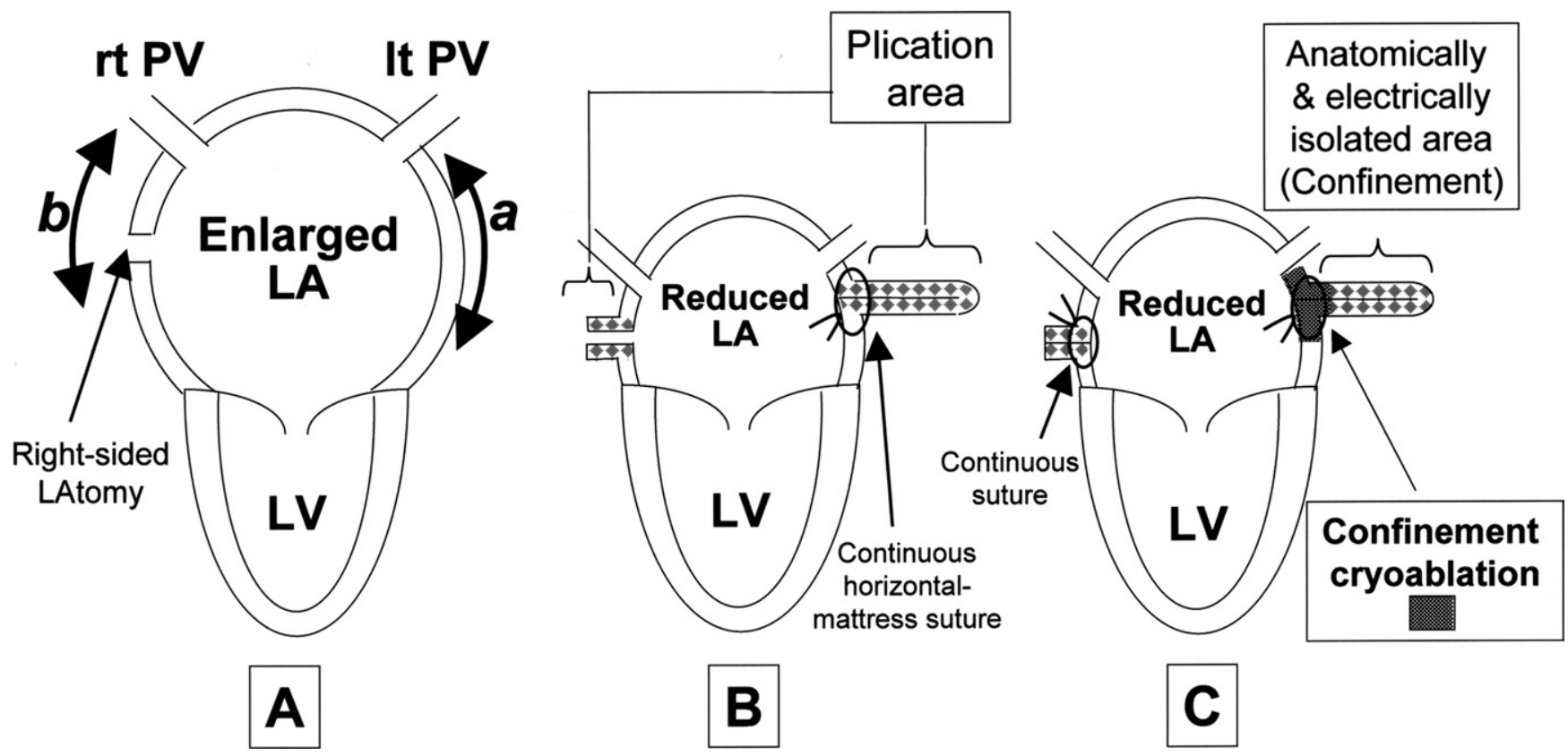

Figure 1. Concept of the less-invasive volume reduction technique by means of left atrial plication and confinement cryoablation. A, Areas for left atrial volume reduction: (a) main area, the redundant left atrial wall between the mitral annulus and the left pulmonary veins; (b) additional area, the left atrial wall along the right-sided left atriotomy. B, Plication of the left atrium. The redundant left atrial area was not excised but plicated toward the outside of the left atrial cavity (anatomic isolation). C, Electrical isolation of the plicated area by means of confinement cryoablation. Cryoablation was applied onto the horizontal mattress suture line (electrical isolation), and then the anatomic and electrical isolation of the plicated area (confinement) was completed. $L A$, Left atrium; $L V$, left ventricle; $P V$, pulmonary vein; $V R$, volume reduction.

Right atrial VR. After the LA was closed, the aorta was declamped. If cardiac rhythm was converted to SR, we did not add the right atrial (RA) maze procedures. Otherwise, we added the RA maze procedures under beating-heart conditions, as shown in Figure 2. If the RA was enlarged, the RA wall was also plicated along the RA suture line.

\section{Postoperative Management and Follow-up}

Pharmacotherapy was homogenous, with no new drugs added throughout the whole study period. To maintain postoperative SR, $\beta$-blockers, digoxin, or both were used unless otherwise contraindicated. Calcium-channel blockers, $\beta$-blockers, or digoxin were also used for the treatment of tachycardia. If AF or atrial flutter occurred, class I antiarrhythmic drugs were used. If they were ineffective, amiodarone or sotalol was used. Cardioversion was performed up to 2 times if the pharmacotherapy was ineffective. After discharge, if patients maintained SR, antiarrhythmic drugs were gradually withdrawn 1 to 3 months after the operation. During follow-up, cardioversion was applied when patients had high-rate arrhythmias, such as AF tachycardia or thromboembolism caused by AF. Warfarin and low-dose aspirin were routinely administered to all patients for 3 months. If the SR was maintained, warfarin could be finished in patients with mitral valve repair or bioprosthetic valve implantation. The above routine was consistent during the whole study period.
Follow-up was complete by outpatient clinic or telephone interview in all patients. Patients were evaluated by means of electrocardiography (ECG), chest roentgenography, and transthoracic echocardiography with pulsed Doppler study at discharge and 3, 12,24 , and 36 months postoperatively. Cardiac rhythm was confirmed by means of regular pulse, a history of palpitation, ECG, and echocardiography. Holter ECG was applied to patients with a history of palpitation. Atrial transport function was evaluated on the basis of the peak $\mathrm{A} / \mathrm{E}$ (ratio of peak A to peak E wave) velocity, as previously described. ${ }^{18}$

\section{Statistical Analysis}

All values are expressed as the mean \pm standard deviation. Statistical analyses comparing the 2 groups were performed with the Wilcoxon rank sum test or the Fisher exact probability test for categoric variables. All statistical analyses were performed with Statview software (Abacus).

\section{Results}

Operative Results

In-hospital results. There was $1(3 \%)$ in-hospital death in the control group caused by severe pneumonia (Table 2). The ratio of patients who underwent the modified Cox maze III or LA maze procedure was not significantly different 
Volume reduction area Cryoablation area

\section{Horizontal-mattress suture}

++++ Suture line

\section{맘ำ}

\section{A}

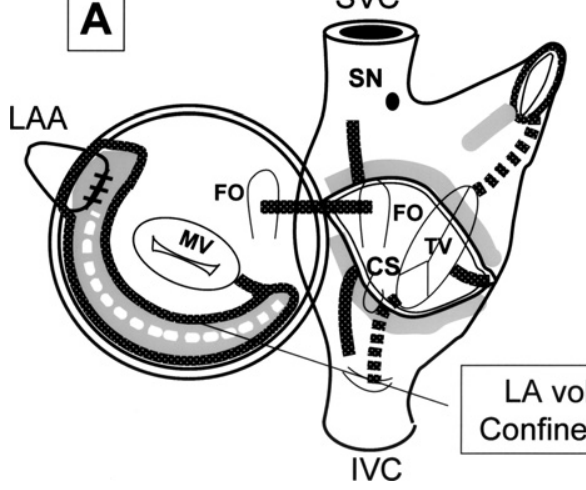

SVC

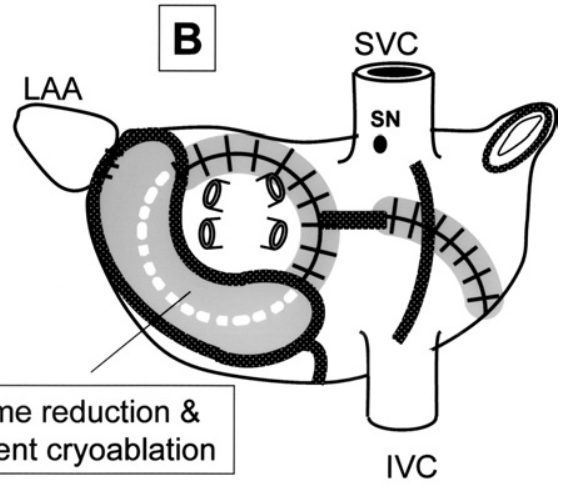

Figure 2. The Cox maze procedure with the volume reduction technique. The redundant left atrial wall between the mitral annulus and the left pulmonary veins was plicated with continuous horizontal mattress sutures (anatomic isolation). Then the plicated area was isolated by means of confinement cryoablation along the suture line (electrical isolation). $L A A$, Left atrial appendage; $S V C$, superior vena cava; $I V C$, inferior vena cava; $F O$, foramen ovale; $S N$, sinus node; $C S$, coronary sinus; $M V$, mitral valve; $T V$, tricuspid valve. between the groups $(75 \%$ vs $70 \%$ in the modified Cox maze III). There were no significant differences in aortic crossclamp time (90 \pm 42 vs $87 \pm 45$ minutes) and cardiopulmonary bypass time (123 \pm 69 vs $132 \pm 55$ minutes). Chest reopening for bleeding was required in $1(3 \%)$ patient in the control group; however, it was not associated with the mazerelated procedures. The amount of chest tube drainage for 12 hours during intensive care unit stay was not significantly different between the groups $(451 \pm 352$ vs $632 \pm 432 \mathrm{~mL})$.

Late results. After discharge, $1(2 \%)$ patient in the VR group and 2 patients in the control group died of noncardiac events ( 1 of pneumonia and 2 of cancer). The late mortality rate was not significantly different between the groups. There was no stroke or thromboembolism during the follow-up period in either group.

\section{Cardiac Rhythm}

Intraoperative SR recovery was observed in all patients. Two $(5 \%)$ patients in the VR group and $2(6 \%)$ patients in the control group received permanent pacemaker implantation because of sinus bradycardia before discharge (Table 2). There was no significant difference in the incidence of perioperative AF between the groups (36\% vs $42 \%$ ).

At discharge, $36(82 \%)$ patients in the VR group and 27 (75\%) patients in the control group were in SR, respectively (Table 3). Patients in the VR group maintained higher SR recovery rates than those in the control group during the follow-up period $(90 \%$ vs $69 \%, 87 \%$ vs $67 \%$, and $100 \%$ vs $64 \%$ at 12,24 , and 36 months, respectively; $P<.05$ at 12 and 24 months). Interestingly, in the VR group 2 patients with recurrent $\mathrm{AF}$ at discharge were recovered to $\mathrm{SR}$ during the follow-up period. In contrast, in the control group AF recurred to 4 patients during the follow-up period who had maintained SR at discharge.

\section{Echocardiography}

Among the patients with SR recovery in both groups, serial changes in LAD and LA transport function after the operation are shown in Table 3. Among the patients with SR in the VR group, the LAD at discharge was significantly smaller than the preoperative LAD (47.6 \pm 6.3 vs $67.1 \pm$ $7.8 \mathrm{~mm}$, respectively; $P<.01$ ). In addition, the LADs at 12 , 24 , and 36 months were also significantly smaller than those at discharge $(42.8 \pm 4.7,41.1 \pm 4.8$, and $42.3 \pm 6.3 \mathrm{~mm}$ vs $47.6 \pm 6.3 \mathrm{~mm}$, respectively; $P<.01$ at 12 and 24 months and $P<.05$ at 36 months). Furthermore, the $\mathrm{A} / \mathrm{E}$ ratios of the patients with SR in the VR group at 3, 12, 24, and 36 months were significantly higher (ie, better) than those at discharge $(0.44 \pm 0.07,0.48 \pm 0.15,0.53 \pm 0.20$, and $0.51 \pm 0.23$ vs $0.35 \pm 0.07$, respectively; $P<.01$ at 12 and 24 months and $P<.05$ at 3 and 36 months). Figure 3 shows the representative echocardiographic findings of the VR maze procedure.

Among the patients with SR in the control group, however, the preoperative LAD was not significantly different from that at discharge or at 3, 12, 24, and 36 months, respectively (Table 3 ). The $A / E$ ratio of the patients with $S R$ in the control group did not improve during the follow-up period, except at 3 months.

\section{Discussion}

The principal finding of the present study is that maze procedures concomitant with the novel VR technique facilitate recovery to $\mathrm{SR}$, as well as maintenance of $\mathrm{SR}$, and 
TABLE 2. Operative results

\begin{tabular}{|c|c|c|c|}
\hline & VR group $(n=44)$ & Control group $(n=36)$ & $P$ value \\
\hline \multicolumn{4}{|l|}{ Maze procedure } \\
\hline Modified Cox maze III & $33(75 \%)$ & $25(70 \%)$ & NS \\
\hline LA maze & $11(25 \%)$ & $11(30 \%)$ & NS \\
\hline \multicolumn{4}{|l|}{ Mitral valve surgery } \\
\hline MVR & $21(48 \%)$ & $15(42 \%)$ & NS \\
\hline MVP & $23(52 \%)$ & $21(58 \%)$ & NS \\
\hline \multicolumn{4}{|l|}{ Concomitant procedures } \\
\hline TAP & $23(52 \%)$ & $19(53 \%)$ & NS \\
\hline AVR & $8(18 \%)$ & $9(25 \%)$ & NS \\
\hline CABG & $3(7 \%)$ & $1(3 \%)$ & NS \\
\hline LVR & $3(7 \%)$ & 0 & NS \\
\hline Aortic surgery & $4(9 \%)$ & $1(3 \%)$ & NS \\
\hline Cardiopulmonary bypass time (min) & $123 \pm 69$ & $132 \pm 55$ & NS \\
\hline Aortic crossclamp time (min) & $90 \pm 42$ & $87 \pm 45$ & NS \\
\hline Chest tube drainage for $12 \mathrm{~h}(\mathrm{~mL})$ & $451 \pm 352$ & $632 \pm 432$ & NS \\
\hline Chest reopening for bleeding & 0 & $1(3 \%)$ & NS \\
\hline Perioperative incidence of $\mathrm{AF}$ & $15(34 \%)$ & $15(42 \%)$ & NS \\
\hline Pacemaker implantation & $2(5 \%)$ & $2(6 \%)$ & NS \\
\hline \multicolumn{4}{|l|}{ In-hospital death } \\
\hline Cardiac & 0 & 0 & NS \\
\hline Noncardiac & 0 & $1(3 \%)$ & NS \\
\hline \multicolumn{4}{|l|}{ Late death } \\
\hline Cardiac & 0 & 0 & NS \\
\hline Noncardiac & $1(2 \%)$ & $2(6 \%)$ & NS \\
\hline
\end{tabular}

$V R$, Volume reduction; $N S$, not significant; $L A$, left atrial; $M V R$, mitral valve replacement; $M V P$, mitral valve plasty; $T A P$, tricuspid annuloplasty; $A V R$, aortic valve replacement; $C A B G$, coronary artery bypass grafting; $L V R$, left ventricular repair; $A F$, atrial fibrillation.

might improve atrial transport function even in patients with long-standing AF and enlarged LAs compared with maze procedures alone. This technique did not extend aortic crossclamp and cardiopulmonary bypass times, which suggest that it is suitable to high-risk patients with poor left ventricular function. In addition, the VR technique might contribute to prevent stroke or thromboembolism by increasing the blood flow velocity in the LA.

Several studies have reported that the LA VR by itself is helpful to SR recovery. ${ }^{13,14,19-21}$ However, all these VR

TABLE 3. Serial changes in cardiac rhythm and echocardiographic data

\begin{tabular}{|c|c|c|c|c|c|c|}
\hline & Preoperative & At discharge & $3 \mathrm{mo}$ & $12 \mathrm{mo}$ & $24 \mathrm{mo}$ & $36 \mathrm{mo}$ \\
\hline \multicolumn{7}{|l|}{ SR $(\%)$} \\
\hline VR & $0(n=44)$ & $82(n=44)$ & $84(n=43)$ & $90 \dagger(\mathrm{n}=30)$ & $87 \dagger(n=15)$ & $100(n=4)$ \\
\hline Control & $0(n=36)$ & $75(n=36)$ & $72(n=36)$ & $69(\mathrm{n}=36)$ & $66(n=35)$ & $65(n=34)$ \\
\hline \multicolumn{7}{|l|}{$\operatorname{LAD}(\mathrm{mm})^{*}$} \\
\hline VR & $\begin{array}{c}67.1 \pm 7.8 \\
(n=44)\end{array}$ & $\begin{aligned} 47.6 & \pm 6.3 \ddagger \\
(n & =36)\end{aligned}$ & $\begin{array}{r}45.7 \pm 5.8 \ddagger \\
(\mathrm{n}=36)\end{array}$ & $\begin{array}{c}42.8 \pm 4.7 \pm \| \\
(n=27)\end{array}$ & $\begin{array}{c}41.1 \pm 4.8 \pm \| \\
(n=15)\end{array}$ & $\begin{array}{c}42.3 \pm 6.3 \neq \S \\
(\mathrm{n}=4)\end{array}$ \\
\hline Control & $\begin{array}{c}64.5 \pm 6.7 \\
(\mathrm{n}=36)\end{array}$ & $\begin{array}{r}62.1 \pm 7.9 \\
(\mathrm{n}=27)\end{array}$ & $\begin{array}{r}63.6 \pm 6.6 \\
(\mathrm{n}=26)\end{array}$ & $\begin{array}{c}62.5 \pm 7.1 \\
(n=25)\end{array}$ & $\begin{array}{c}60.8 \pm 8.3 \\
(n=23)\end{array}$ & $\begin{array}{c}59.7 \pm 9.6 \\
(n=22)\end{array}$ \\
\hline \multicolumn{7}{|l|}{ A/E ratio* } \\
\hline VR & $\begin{array}{c}- \\
(n=44)\end{array}$ & $\begin{array}{c}0.37 \pm 0.10 \dagger \\
(\mathrm{n}=36)\end{array}$ & $\begin{array}{c}0.44 \pm 0.07 \pm \S \\
(\mathrm{n}=36)\end{array}$ & $\begin{array}{c}0.48 \pm 0.15 \neq \| \\
(n=27)\end{array}$ & $\begin{array}{c}0.53 \pm 0.20 \pm \| \\
(n=15)\end{array}$ & $\begin{array}{c}0.51 \pm 0.23 \ddagger \S \\
(n=4)\end{array}$ \\
\hline Control & $\begin{array}{c}- \\
(n=36)\end{array}$ & $\begin{array}{c}0.30 \pm 0.11 \\
(\mathrm{n}=27)\end{array}$ & $\begin{array}{c}0.35 \pm 0.07 \S \\
(n=26)\end{array}$ & $\begin{array}{c}0.33 \pm 0.10 \\
(n=25)\end{array}$ & $\begin{array}{c}0.35 \pm 0.13 \\
(\mathrm{n}=23)\end{array}$ & $\begin{array}{c}0.32 \pm 0.09 \\
(n=22)\end{array}$ \\
\hline
\end{tabular}

$S R$, Sinus rhythm; $V R$, volume reduction; $L A D$, left atrial diameter; $A / E$, Doppler ratio of late (peak $A$ wave) to early (peak $E$ wave) diastolic transmitral flow velocity. *Left atrial diameter and $A / E$ ratios were evaluated only in the patients with sinus rhythm at each time point except before the operation. $\dagger P<$ .05 and $\ddagger P<.01$ versus control; $\S P<.05$ and $\| P<.01$ versus at discharge. 
Preop.

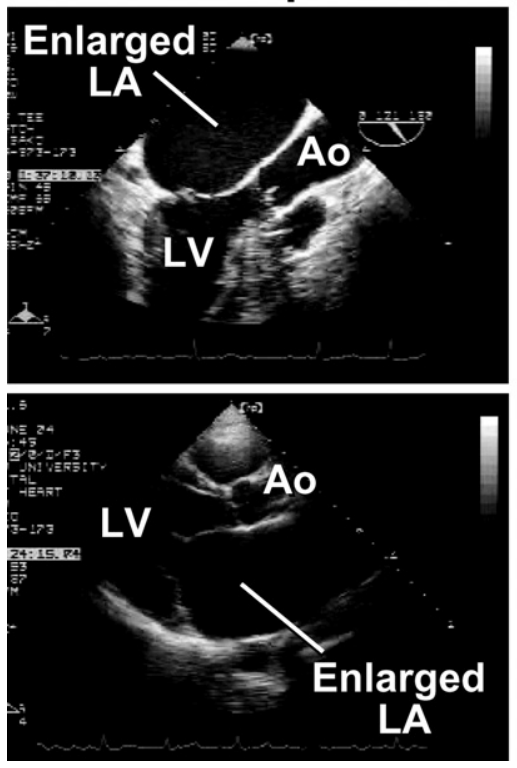

Postop.

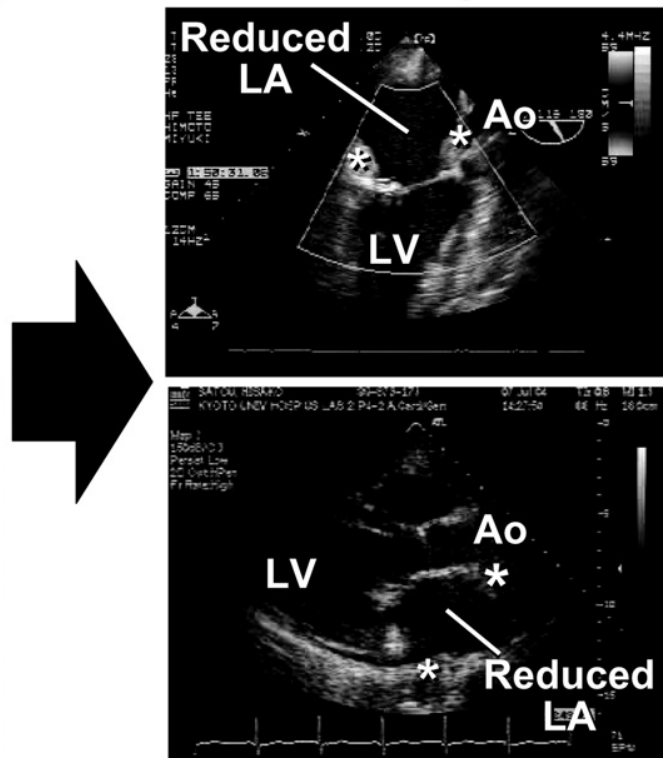

Figure 3. Representative echocardiographic findings of the volume reduction Cox maze procedure. Preoperative and postoperative echocardiographic findings of a 50-year-old woman with the volume reduction Cox maze procedure are shown. The left atrium was severely enlarged preoperatively (left atrial diameter, $76 \mathrm{~mm}$ ); however, the diameter was considerably reduced to $46 \mathrm{~mm}$ by using the volume reduction Cox maze procedure, and the rhythm was converted to sinus rhythm. Upper (lower) panels, Transesophageal (transthoracic) echocardiography. Asterisks, left atrial plicated area. $L A$, Left atrium; $A o$, aorta; $L V$, left ventricle. procedures were based on the cut-and-sew technique. Even the original Cox maze procedure alone is relatively time consuming and technically demanding, and the aggressive VR procedures with the cut-and-sew technique further extend cardiac ischemic time, affect left ventricular function, increase postoperative bleeding, and might increase perioperative mortality and morbidity.

To solve these problems, we have established the nobleeding VR technique by means of LA plication and confinement cryoablation. The major advantages of our technique are as follows: (1) LA plication by means of continuous horizontal mattress sutures instead of additional cut-and-sew procedures drastically reduces the crossclamp time and the risk of bleeding, and (2) confinement cryoablation establishes the electrical isolation of the PV and the plicated LA area simultaneously. It takes approximately 15 to 20 minutes on average to complete our maze ablation on the LA side, including the VR technique, in part because VR makes the cryoablation line shorter. Furthermore, cryoablation might be advantageous in the aspect of the minimal damage to the endocardium and creation of the transmural homogeneous lesions. 5,16

A large LAD with mitral valve disease is a predictor for late recurrent $\mathrm{AF}$ after the Cox maze procedure. ${ }^{9,10} \mathrm{We}$ speculate that the Cox maze procedure is effective in those tough patients but that it might provide insufficient elimination of LA area for macroreentry circuit formation because of the enlarged LA. The Cox maze procedure for mitral valve disease is the only effective procedure to facilitate the recovery of $\mathrm{SR},{ }^{5,22}$ and an additional LA VR technique to eliminate the macroreentry circuit formation area might facilitate SR recovery. Some institutions do not apply the Cox maze procedure to patients with AF with the difficult conditions described above to seemingly improve the success rate. ${ }^{16,23}$ However, these high-risk patients often have low left ventricular function, and therefore recovery to SR will improve postoperative cardiac function and consequently might improve morbidity and mortality. This potential merit is prominent, particularly in patients who require intra-aortic balloon pumping or catecholamine before or after the operation.

The VR technique might contribute not only to SR recovery but also to maintenance of SR during the late phase. In the present study $2(6 \%)$ patients in the VR group recovered SR during the follow-up period. On the contrary, $4(11 \%)$ patients in the control group had recurrent AF, although they were administered antiarrhythmic drugs. We speculate that the maintenance of SR by the VR might possibly be due to a decrease in LA wall stress according to Laplace's law (ie, less burden for atrial myocardial cells at any LA pressure) and in primary stimulation of fibrillation, as well as elimination of area for the macroreentry circuit. ${ }^{21}$

It has been controversial whether the Cox maze procedure alone reduces LA size and recovers atrial contraction postoperatively. ${ }^{21,24,25}$ Even in the patients with SR recovery in the control group, the LA size did not reduce and the $\mathrm{A} / \mathrm{E}$ ratio did not increase during the follow-up period (Table 3). In addition, LA transport function recovered during the follow-up period only in the patients with SR recovery in the VR group (ie, not in patients in the control group, regardless of rhythm). The results suggest that the 
VR technique is desirable for the patients with AF who are not well indicated for maze procedures.

There are several limitations in the present study. First, this study was not a prospective randomized study. The operation was not randomly assigned for the VR group or the control group in a certain period. In addition, the follow-up period was only 3 years because patients in the VR group were relatively new and had shorter follow-up times than those of the control group. Further follow-up, especially for the VR group, would be necessary. Next we used 2 types of maze procedures. The SR recovery rates in both groups at discharge were somewhat low compared with those of previous reports. ${ }^{5,9,10,19}$ This might be partly because the patient population in the present study had mitral valve disease with long-standing AF and a large LAD. In addition, use or not of RA maze procedures might be another reason. However, the ratio of patients who underwent the modified Cox maze III or LA maze procedure was not significantly different between the groups. Furthermore, among the patients with the modified Cox maze III procedure in both groups, SR recovery rates were significantly different between the VR and the control groups ( $92 \%$ vs $68 \%, P<.05$ ); however, operative results might have changed if all patients had undergone the modified Cox maze III procedure. Finally, the peak $\mathrm{A} / \mathrm{E}$ ratio cannot entirely be an indicator of atrial transport function. Other evaluation for atrial function might be necessary. ${ }^{26}$

In conclusion, this safe and thus far potent VR technique that catheter-based ablation cannot copy might extend indication for the Cox maze procedure to patients with AF with difficult conditions. Further study with larger numbers of patients and longer follow-up periods, especially in a prospective and randomized fashion, will be warranted.

\section{References}

1. Cox JL. The surgical treatment of atrial fibrillation. IV. Surgical technique. J Thorac Cardiovasc Surg. 1991;101:584-92.

2. Cox JL, Jaquiss RD, Schuessler RB, Boineau JP. Modification of the maze procedure for atrial flutter and atrial fibrillation. II. Surgical technique of the maze III procedure. J Thorac Cardiovasc Surg. 1995;110:485-95.

3. Cox JL, Ad N, Palazzo T, Fitzpatrick S, Suyderhoud JP, DeGroot KW, et al. Current status of the Maze procedure for the treatment of atrial fibrillation. Semin Thorac Cardiovasc Surg. 2000;12:15-9.

4. Cox JL. Intraoperative options for treating atrial fibrillation associated with mitral valve disease. J Thorac Cardiovasc Surg. 2001; $122: 212-5$.

5. Melo J, Adragao P, Neves J, Ferreira M, Timoteo A, Santiago T, et al. Endocardial and epicardial radiofrequency ablation in the treatment of atrial fibrillation with a new intra-operative device. Eur J Cardiothorac Surg. 2000;18:182-6.

6. Dong J, Calkins H. Technology insight: catheter ablation of the pulmonary veins in the treatment of atrial fibrillation. Nat Clin Pract Cardiovasc Med. 2005;2:159-66.
7. Sueda T, Imai K, Orihashi K, Okada K, Ban K, Hamamoto M. Midterm results of pulmonary vein isolation for the elimination of chronic atrial fibrillation. Ann Thorac Surg. 2005;79:521-5.

8. Gaita F, Riccardi R, Caponi D, Shah D, Garberoglio L, Vivalda L, et al. Linear cryoablation of the left atrium versus pulmonary vein cryoisolation in patients with permanent atrial fibrillation and valvular heart disease: correlation of electroanatomic mapping and long-term clinical results. Circulation. 2005;111:136-42.

9. Gaynor SL, Schuessler RB, Bailey MS, Ishii Y, Boineau JP, Gleva MJ, et al. Surgical treatment of atrial fibrillation: predictors of late recurrence. J Thorac Cardiovasc Surg. 2005;129:104-11.

10. Gillinov AM, Sirak J, Blackstone EH, McCarthy PM, Rajeswaran J, Pettersson G, et al. The Cox maze procedure in mitral valve disease: predictors of recurrent atrial fibrillation. J Thorac Cardiovasc Surg. 2005; 130:1653-60.

11. Henry WL, Morganroth J, Pearlman AS, Clark CE, Redwood DR, Itscoitz SB, et al. Relation between echocardiographically determined left atrial size and atrial fibrillation. Circulation. 1976;53:273-9.

12. Kamata J, Kawazoe K, Izumoto H, Kitahara H, Shiina Y, Sato Y, et al. Predictors of sinus rhythm restoration after Cox maze procedure concomitant with other cardiac operations. Ann Thorac Surg. 1997;64: 394-8.

13. Winlaw DS, Farnsworth AE, Macdonald PS, Mundy JA, Spratt PM. Left atrial reduction: the forgotten Batista. Lancet. 1998;351:879-80.

14. Sankar NM, Farnsworth AE. Left atrial reduction for chronic atrial fibrillation associated with mitral valve disease. Ann Thorac Surg. 1998;66:254-6.

15. Chen MC, Guo GB, Chang JP, Yeh KH, Fu M. Radiofrequency and cryoablation of atrial fibrillation in patients undergoing valvular operations. Ann Thorac Surg. 1998;65:1666-72.

16. Nakajima H, Kobayashi J, Bando K, Niwaya K, Tagusari O, Sasako Y, et al. The effect of cryo-maze procedure on early and intermediate term outcome in mitral valve disease: case matched study. Circulation. 2002;106(suppl I):I46-50.

17. Imai K, Sueda T, Orihashi K, Watari M, Matsuura Y. Clinical analysis of results of a simple left atrial procedure for chronic atrial fibrillation. Ann Thorac Surg. 2001;71:577-81.

18. Ishii Y, Nitta T, Fujii M, Ogasawara H, Iwaki H, Ohkubo N, et al. Serial change in the atrial transport function after the radial incision approach. Ann Thorac Surg. 2001;71:572-6.

19. Scherer M, Dzemali O, Aybek T, Wimmer-Greinecker G, Moritz A. Impact of left atrial size reduction on chronic atrial fibrillation in mitral valve surgery. J Heart Valve Dis. 2003;12:469-74.

20. Romano MA, Bach DS, Pagani FD, Prager RL, Deeb GM, Bolling SF. Atrial reduction plasty Cox maze procedure: extended indications for atrial fibrillation surgery. Ann Thorac Surg. 2004;77:1282-7.

21. Chen MC, Chang JP, Guo GB, Chang HW. Atrial size reduction as a predictor of the success of radiofrequency maze procedure for chronic atrial fibrillation in patients undergoing concomitant valvular surgery. J Cardiovasc Electrophysiol. 2001;12:867-74.

22. Bando K, Kobayashi J, Kosakai Y, Hirata M, Sasako Y, Nakatani S, et al. Impact of Cox maze procedure on outcome in patients with atrial fibrillation and mitral valve disease. J Thorac Cardiovasc Surg. 2002; 124:575-83.

23. Kosakai Y. Treatment of atrial fibrillation using the Maze procedure: the Japanese experience. Semin Thorac Cardiovasc Surg. 2000; $12: 44-52$.

24. Jessurun ER, van Hemel NM, Kelder JC, Defauw JA, Brutel de la Riviere A, Ernst JM, et al. The effect of maze operations on atrial volume. Ann Thorac Surg. 2003;75:51-6.

25. Yuda S, Nakatani S, Kosakai Y, Yamagishi M, Miyatake K. Longterm follow-up of atrial contraction after the maze procedure in patients with mitral valve disease. J Am Coll Cardiol. 2001;37:1622-7.

26. Yamanaka K, Fujita M, Doi K, Tsuneyoshi H, Yamazato A, Ueno K, et al. Multislice computed tomography accurately quantifies the left atrial size and function after the maze procedure. Circulation. 2006; 114(Suppl):15-9. 